\title{
O CINEMA E A EDUCAÇÃO - AS REDES DE SIGNIFICAÇÕES E SUBJETIVIDADES TECIDAS NAS/COM AS PRÁTICAS E PESQUISAS
}

\author{
Adriana Hoffmann Fernandes ${ }^{1}$ \\ Aline Monteiro ${ }^{2}$ \\ Maria da Conceição Silva Soares ${ }^{3}$
}

O cinema, a princípio, constitui um espaço-tempo em que nos permitimos, praticamente sem defensivas, sonhar e imaginar o mundo e a nós mesmos. Na sala escura ou em qualquer outro ambiente propício para a exibição de um filme, hipnotizados diante de uma tela, nos permitimos, por algumas poucas horas, tirar os pés do chão e nos deixar levar em viagens que nos transportam tanto ao paraíso como ao inferno, tanto às profundezas da terra como ao espaço sideral, tanto ao cume das montanhas como ao fundo do mar, tanto a um passado improvável como a um futuro inventado, tanto a detalhes despercebidos do cotidiano, como ao estranho-familiar de um mundo fantástico e sobrenatural. Mergulhamos com quase todos os sentidos nas narrativas cinematográficas, em total cumplicidade com o modus operandi do cinema, isto é, com absoluta disponibilidade para tomar como reais e críveis enredos e personagens, fatos e ficções, ações e vacúolos, lugares e tempos, conhecidos, desconhecidos e até impensáveis, pois, apenas com esse desprendimento podemos experimentar/vivenciar sensações, emoções, descobertas, alegrias, dores, paixões, medos e horrores, entre tantos sentimentos outros e dos outros que as situações vividas nos/com os filmes criam para nós e em nós.

Essa atitude de imersão e aquiescência, segundo Arlindo Machado (2007), é necessária e, ao mesmo tempo, produzida na contingência da narrativa cinematográfica ser sempre vivida pelo espectador como um presente virtual, como uma simulação do processo do sonho, em que a história que se sucede diante de nós, aparece imediatamente aos nossos olhos e ouvidos com efeito de realidade e nós entramos nela. De repente estamos lá, testemunhando os acontecimentos. Nesse processo, que ele chama de participação onírica, não seríamos outra coisa que "vidência pura, destituída de corpo" (Machado, 2007, p. 20).

\footnotetext{
${ }^{1}$ Doutora em Educação - Universidade do Estado do Rio de Janeiro (UERJ) - Rio de Janeiro, RJ - Brasil. Professora adjunta - Universidade Federal do Estado do Rio de Janeiro (UNIRIO) - Rio de Janeiro, RJ - Brasil. E-mail: hoffadri58@gmail.com

${ }^{2}$ Universidade Federal do Rio de Janeiro (UFRJ) - Rio de Janeiro, RJ - Brasil. E-mail: hoffadri58@gmail.com

${ }^{3}$ Doutora e Mestre em Educação - Universidade Federal do Espírito Santo (UFES) - Vitória, ES - Brasil. Professora adjunta - Universidade do Estado do Rio de Janeiro (UERJ) - Rio de Janeiro, RJ - Brasil. ceicavix@gmail.com
}

(C) ETD-Educação Temática Digital Campinas, SP v.19 n.2 p. 307-315 abr./jun. 2017 
Por esse viés, podemos pensar que, para além de agenciamentos e endereçamentos, o cinema produz presenças. Traz pessoas, coisas, lugares, temporalidades e acontecimentos para perto de nós, para diante de nós. Contudo, apesar da centralidade da audição e do olhar nesse processo, essas presenças afetam nossos corpos e nossas sensibilidades, produzem "tilts" em todo o nosso ser, como disse Barthes (1984) em relação à fotografia. Elas sugerem comportamentos convenientes, condenáveis e imprevisíveis, interrompem fluxos cognitivos habituais, condensam emoções em gestos e rituais, apresentam modos de fazer a serem imitados, recusados ou transformados, invocando, por vezes, uma combinatória de lógicas operacionais milenares.

Tais presenças produzidas com o cinema, com o que ele nos faz testemunhar, nos provocam, nos interrogam e nos convocam a imaginar/experimentar uma atitude/ação possível diante dos acontecimentos e, dessa forma, alargam nossas redes de saberes-fazeres e desencadeiam processos de subjetivação.

Pensar as relações entre o cinema e a educação pela perspectiva da produção de presença, entendendo seus processos formativos entrelaçados e articulados a tantas outras formas de abordagem, cria possibilidades fecundas para analisarmos e tensionarmos aprendizagens coletivas e inventivas por meio de problematizações, aprendizagens culturais, agenciamentos de formas de subjetividade e processos de subjetivação e a criação de conhecimentos nas contingências da experiência estética.

Trata-se, primeiramente, de questionar como e o quê se aprende na/com a vida sensível, que estética o cinema traz, de compreender a emoção como um movimento que nos toma, nos toca, sem que saibamos realmente o que representa para nós. Um movimento que para Didi-Huberman (2016) está em nós, mas, ao mesmo tempo para além de nós, portanto, um movimento afetivo, profundo e que foge à razão. As emoções, segundo esse autor, passam por sinais corporais, gestos e rituais que, como fósseis em movimento, têm uma história longa e inconsciente. As narrativas fílmicas, assim como outros tipos de imagens e sons, concentram muitas coisas, inclusive gestos expressivos das emoções que atravessam a história e que agem em nós e sobre nós. Para Didi-Huberman (2016), nós transmitimos as emoções por meio de gestos e mímicas, o que implica compreendê-las como algo adquirido. Com o evento afetivo da emoção, segundo o autor, emerge um tipo de conhecimento sensível e transformador.

Nas culturas visuais, e mais precisamente nas culturas audiovisuais, as narrativas fílmicas, entre outras audiovisualidades, tornam as coisas visíveis e inteligíveis para nós. Elas criam aparições e nos levam a experimentar o mundo como imagem, estetizando-o. E que formações essas audiovisualidades do cinema nos trazem? Que aprendizados implícitos operam essas experiências?

(C) ETD-Educação Temática Digital Campinas, SP v.19 n.2 p.307-315 abr./jun. 2017 
Para Christoph Wulf (2013), o aprendizado cultural é parte da experiência estética, através da qual aprendemos a sentir, expressar e modificar sentimentos. Os processos miméticos que envolvem esse aprendizado, para ele, são formas produtivas de imitação, as quais produzem sempre diferença em relação ao modelo original. O cinema, assim como a literatura e outras narrativas, fornece repertórios para o imaginário individual e coletivo onde se forjam os modelos a serem imitados. Nas palavras de Wulf $(2013$, p. 14):

Com a ajuda da imaginação também são incorporadas em processos miméticos as imagens de outras pessoas, outros mundos e outras vidas. A educação pode ser compreendida como um processo mimético no qual a crítica ao modelo também desempenha um papel importante.

A mímica, pensada não apenas como cópia e reprodução, mas também como encenação, burla e performance, como mimesis, nos remete ao aspecto sensorial da experiência, com ênfase no movimento dos corpos e nas pessoas em ação. Ainda segundo Wulf (2013, p. 54):

Em grande medida, o aprendizado cultural é aprendizado mimético, e está no centro de muitos processos de educação e autoaprendizado. Ele está direcionado a outras pessoas, comunidades sociais e heranças culturais e garante que eles serão mantidos vivos. O aprendizado mimético é uma forma sensorial e corporal de aprendizado em que as imagens, esquemas e movimentos necessários para realizar ações são aprendidos. Isso ocorre, em grande medida inconscientemente e é isso que é responsável pelos efeitos mais duradouros que exercem um importante papel em todas as áreas do desenvolvimento cultural.

A ideia de aprendizado cultural, corporal e sensorial, para além de uma pretensa razão meramente instrumental, nos leva à produção de um conhecimento prático aprendido através de processos miméticos e que tornam o indivíduo capaz de agir. Ainda segundo Wulf (2013, p. 53), tais processos "envolvem produtos de história e cultura, cenas, arranjos e performances", constituindo um dos mais importantes modos de transmissão cultural.

A experiência estética, segundo Guimarães (2006), articula múltiplas racionalidades e possibilita a presentificação de experiências por meio de performances artificiais, colocando em jogo uma relação experimental entre a significação de objetos estéticos e a nossa experiência, isto é, nos permite fazer da experiência as experiências presentificadas pelos objetos, entre eles as imagens. Como esclarece o autor, a experiência estética não significa nem recorrer ao já sabido nem adotar, de imediato, o que é desconhecido. Ao invés disso, ela permite alargar e corrigir uma concepção prévia ou introduzir um ponto de vista desviante, e, dessa forma, problematizador. 
(...) a experiência procura integrar o que é estranho ao familiar (isto é, ao quadro de referências que era familiar), mas alargando e enriquecendo aquilo que até então constituía o limite de todo real possível. Como resposta a uma 'coerção acontecimental', a experiência estética é uma mobilização multidimensional (cognitiva, volitiva e emotiva), produzida no confronto com um objeto problemático que é experimentado numa situação não familiar. (GUIMARÃES, 2006, p. 16)

Trata-se, como sintetiza esse autor, de compreender que o mundo ficcional não nos tira daquele que habitamos, mas que nele entreabre outros mundos. Trata-se de abrir mundos dentro do mundo, não separados entre si, mas em interação.

Em um projeto ousado e singular, e na contramão do que considera uma vocação hermenêutica das Humanidades, Gumbrecht (2010) se aventura em busca de novas epistemologias para abordar o que há no espaço da experiência não conceitual. No caminho intelectual que empreende com esse objetivo, a produção da presença potencializa experiências que podem dispensar o que seria uma redução hermenêutica da significação. Trata-se, com o conceito de presença, de se ocupar do que não é apreensível exclusivamente por uma relação de sentido, ou seja, do que o sentido não consegue transmitir. Para ele, a experiência estética oscila entre efeitos de presença e efeitos de sentido.

Para Gumbrecht (2013) a experiência estética pode suscitar epifania, alguma coisa como uma apreensão súbita de algo a partir da presentificação, levando, por exemplo, a ocorrência de um pensamento único e inspirador. Assim, no uso do cinema, como de outros artefatos culturais nas práticas de ensino, a presentificação e a epifania, mais do que a orientação e a interpretação pedagógicas, são apontadas como modalidades possíveis para a fruição das obras sem tornar a experiência estética uma obrigação para os estudantes e sem fazer "alusão a quaisquer valores que estivessem além do sentimento intrínseco de intensidade que ela pode causar" (Gumbrecht, 2013, p. 125).

Esses diferentes pontos de vista sobre a experiência estética e suas possibilidades para a educação, nos apontam que para além da convicção de que tal experiência articula diferentes racionalidades e redes afetivas-cognitivas-sensíveis não há um único modo, sistemático ou pedagógico, para conduzir as práticas educativas e as pesquisas que fazem dialogar cinema e educação.

Partindo dessa premissa, reunimos neste dossiê artigos de pesquisadores de diversas instituições que se ocupam das relações entre cinema e educação com olhares teóricosmetodológicos e epistemológicos múltiplos, produzindo tensões e composições possíveis entre as diferentes abordagens. Artigos que pensam as relações entre cinema e educação entremeando reflexões sobre formação, estética, olhar e alteridade, temas que se articulam e dialogam de diferentes modos.

\section{(C) ETD-Educação Temática Digital Campinas, SP v.19 $\quad$ n.2 $\quad$ p. 307-315 abr./jun. 2017}


No artigo Olhar em busca do belo que conforta: o outro diante do cinema brasileiro - as autoras Rosa Fischer e Ananda Vargas Hilgert discutem de forma provocadora o tema da alteridade relacionando-o ao conceito do belo/beleza na narrativa cinematográfica. As autoras partem do pressuposto de que o cinema desestabiliza e buscam entender o cinema como provocação do pensamento. Assim, entendem a relação com a educação como uma educação para a arte e para a sensibilidade, no sentido do convite a uma experiência éticoestética. Em seu artigo trazem dados de uma pesquisa referentes a jovens universitários estrangeiros para analisar dados de uma prática pedagógica, vivida durante dois anos, no decorrer das atividades de uma disciplina sobre filmes brasileiros destinada a alunos estrangeiros, como parte do Programa de Português para Estrangeiros. Estudantes que, ao viver um período de suas histórias acadêmicas no Brasil, tiveram a oportunidade de ver e discutir filmes brasileiros.

Como esses estudantes estariam entendendo o belo, ou seja, que concepção de arte trariam eles? $O$ artigo traz várias reflexões interessantes sobre essas escolhas percebidas na pesquisa. Nós, aqui, pensando junto, nos perguntamos junto com as autoras: como o olhar de fora, do outro, pensa a nós mesmos? Como a alteridade é vivida e percebida pelo outro com seu olhar estrangeiro, de outra cultura? Pode também o diferente, o outro, a nova cultura ser vista como o não belo? Essas e outras questões são discutidas de forma instigante no artigo.

O artigo Infâncias, olhares e montagens: experiências e pesquisas com crianças e educação traz a discussão desse outro da infância. Apresenta reflexões a partir de duas investigações desenvolvolvidas em torno do cinema, imagem cinematográfica e infância.

Dialogando com Deleuze, os autores Cesar Leite, Adriana Regina Isler Pereira Leite e Rafael Christofoletti desenvolvem seu ensaio procurando perceber os objetos de linguagem, olhares e sensações produzidos pelas crianças. Discutem como o pesquisar com as crianças parece fazer emergir um novo modo de fazer pesquisa, uma pesquisa como experiência que vai sendo construída na interlocução entre os pesquisadores e as crianças.

Nesse sentido, os autores discutem o conceito de biopolítica de Foucault e pensam o processo da pesquisa com as crianças em diálogo com Agamben, Benjamin e outros autores através dos quais se percebe o processo do educar o olhar na perspectiva do sair, estar fora, dentro de um estado mental de atenção que busca uma mudança produzida e construída no caminhar do olhar com o outro. Um diálogo com a estética desse caminhar com as imagens.

A questão da formação do olhar também aparece no artigo Escolhas Metodológicas nas Pesquisas em Cinema e Educação: é possível falar em cinema de formação? no qual são

\author{
(C) ETD-Educação Temática Digital Campinas, SP v.19 $\quad$ n.2 $\quad$ p. 307-315 abr./jun. 2017
}


estabelecidas relações entre o cinema e a literatura ao pensar sobre como um modo de ser da literatura pode dar pistas para um modo de ser do cinema.

Desse modo, as autoras Fabiana Marcello e Lisli Seibert discutem e relacionam o gênero literário "romance de formação" ao conceito de "filmes de formação" por elas criado. Quais são os diálogos possíveis entre romance de formação e filmes de formação? A formação no artigo é entendida no sentido de "experiência que incide sobre nosso inacabamento". Além de discutir a complexidade da questão da (trans)formação que os dois termos relacionados à literatura e ao cinema trazem nessa analogia de inacabamento, as autoras buscam delinear novas relações e estratégias metodológicas para a pesquisa em cinema e educação a partir da reflexão sobre romances e filmes específicos e seu caráter de formação.

O artigo $O$ cinema como formação: a escola como mediadora da relação entre jovens e filmes comunica e discute achados produzidos com uma pesquisa realizada com jovens de uma escola de formação técnica do ensino médio integrado, de Formação de Técnico Audiovisual, enredando cinema e educação. O campo de pesquisa foi constituído por rodas de leitura e exibições de filmes seguidas debates, num processo de cooperação científica entre duas universidades e a escola onde foi realizado o projeto.

A pesquisa dos autores Adriana Hoffmann e Pedro Garcia apontou que as rodas de leitura possibilitaram alargar o debate sobre as vivências dos jovens com o cinema, levando à reflexão sobre o papel mediador da escola na relação entre cinema e juventude. As narrativas forjadas nos debates sugerem que nessa relação a escola atua como sensibilizadora e desautomazidadora, questionando a crítica que considera o uso das narrativas fílmicas na sala de aula como algo que leva a um empobrecimento pedagógico, o que corrobora para a defesa do cinema como formação.

O texto indica que a assistência em conjunto de filmes seguida de rodas de debates operam no espaço-tempo para a constituição de uma comunidade de interpretação, partilha e produção de sentidos. Trata-se da constituição e transformação do olhar numa dimensão formadora da relação com o cinema na escola.

A questão do olhar, agora com o foco na formação de professores, é o tema do artigo El@s voltam no sábado: enredos do Laseb de Educação e Cinema. Nele, as autoras Inês Teixeira e Ana Lucia de Faria Azevedo analisam questões e aspectos relativos a um Curso de Especialização em Educação e Cinema destinado à formação continuada de professores/as de escolas públicas de Educação Básica, realizado mediante convênio entre a Faculdade de Educação da UFMG e a Secretaria Municipal de Ensino de Belo Horizonte (RME/BH). O artigo se ocupa da sexta edição do Programa de Pós-Graduação Lato Sensu para Educadores da Educação Básica (Laseb), criado em 2006 e subsidiado pelo MEC, que foi a primeira e única

(c) ETD-Educação Temática Digital Campinas, SP v.19 $\quad$ n.2 $\quad$ p. 307-315 abr./jun. 2017 
turma de especialização em Educação e Cinema, tendo contado com a participação de 40 educadores/as da Educação Infantil, do Ensino Fundamental I e II, bem como diretores e bibliotecários de escolas da rede.

A análise do "Laseb do Cinema", apresentada no artigo, seguiu caminhos metodológicos constituídos a partir do levantamento de documentos, tendo como fonte o acervo do Programa e da coordenação do Curso, Entre os documentos analisados o artigo destaca a proposta curricular e as atividades de planejamento e elaboração de monografias.

Conforme o texto, o objetivo central do curso foi o de contribuir para a formação estética e a reinvenção das práticas pedagógicas dos/as educadores/as com cinema e audiovisual, defendendo que esses artefatos "devem ser trazidos à escola e à docência para que a humanizem, enriqueçam e ampliem a educação de crianças, jovens e adultos".

Em A estética negra de Zózimo Bulbul em cena: novas possibilidades para pensar cinema, currículo e formação de professores, os autores Adriana Fresquet e Fábio José Paz da Rosa trabalham o contexto de formação docente sob outra ótica. Apresentam um ensaio que se propõe a analisar a cinematografia negra de Bulbul enquanto possibilidade de educação etnorracial em contextos de formação docente. No caminho narrativo que constrói para apresentar sua argumentação, o ensaio começa contextualizando a trajetória educacional e artística do cineasta, trazendo questões produzidas por ele a partir de suas memórias relacionadas à escola, com o intuito de refletir como seu cinema pensa o mundo e suas tensões, entre elas o sistema escolar e o preconceito racial, e também questões engendradas pela sua formação artística, especialmente no que diz respeito à produção imagética dos negros que o levou a produzir novas/outras imagens com o cinema.

Em um segundo momento, o texto busca argumentar sobre a operatividade das questões produzidas com o cinema de Bulbul, para pensar os currículos e as negritudes em uma perspectiva multi/intercultural na formação de professores. As questões que se impõem são: Qual o espaço para construção de novas imagens dos negros em nossas aulas, grupos de pesquisa e eventos acadêmicos? É possível omitir a contribuição da população negra na construção de novas formas de se visibilizar? Por fim, o ensaio busca inter-relacionar tais temáticas ao propor uma análise fílmica do primeiro curta-metragem produzido por Zózimo, Alma no Olho, de 1974, assumindo conhecimentos e saberes em questão produzidos entre a realidade e a ficção, entre estranhamentos e emancipações dos sujeitos-espectadores.

Estabelecer uma aproximação entre a noção de iconoclastia e a história da educação por meio da análise de filmes sobre crianças é a proposta do artigo A iconoclastia no cinema e na pedagogia - reflexões a partir de dois filmes infantis dos anos de 1930 da autora Ines Dussel. A partir das obras cinematográficas Emil und die Detektive (Alemanha, Gerhard

(C) ETD-Educação Temática Digital Campinas, SP v.19 n.2 p.307-315 abr./jun. 2017 
Lamprecht, 1931) e Zéro de conduite (França, Jean Vigo, 1933), que contêm várias cenas em que monumentos e outros ícones das autoridades tradicionais são profanados, o texto reflete sobre a "ambivalência do gesto iconoclasta, como uma história da revolta contra as autoridades constituídas, mas também como um movimento que permanece em um círculo de 'fascinação, repulsão, destruição, expiação... gerado pela adoração da imagem proibida'(LATOUR, 2010, p.70)". Trata-se, segundo a reflexão proposta, de um questionamento necessário tendo em vista a abertura de novos caminhos para outra política do visual.

O artigo, que põe em questão os vínculos entre iconoclastia e pedagogia, se estrutura a partir de três linhas de reflexão, a iconoclastia na pedagogia, no cinema e, particularmente, no cinema infantil dos anos 30, a partir das quais puxa/tece fios para indagar a produção historiográfica e teórica do campo. Nesse processo, a iconoclastia é tomada como uma noção que permite pensar simultaneamente sobre as qualidades materiais, objetivas e afetivas da imagem.

De acordo com o texto, a reflexão realizada em relação ao que se apresenta como iconoclastia nos filmes infantis dos anos de 1930 assinala a potência que teve essa crítica em seu momento, mas também indica suas limitações, não somente em relação ao modo como seus gestos foram apropriados, como também pela sua própria dificuldade em reconhecer sua fascinação com as imagens.

No artigo Mulheres em projetos de educação pelo/para o cinema as autoras Rosália Duarte, Milene Gusmão e Raquel Costa trazem a trajetória de cinco mulheres pioneiras em ações que relacionam educação e cinema a partir de 1950. Segundo as autoras, as trajetórias dessas personagens construíram uma tradição de forte atuação feminina no campo da área de Cinema e Educação. O artigo busca indagar como essas mulheres passaram a ocupar lugares de mediação nas experiências de formação pelo/para o cinema no contexto histórico do século XX no Brasil e na América Latina numa época em que os processos de formação ainda estavam muito marcados pela presença masculina. As mulheres cujas trajetórias são analisadas são America Penichet, Alicia Veiga, Irene Tavares de Sá, Hilda Soares e Marialva Monteiro. Todas têm em comum os processos de formação pelo cinema e a presença da Igreja Católica em seus percursos.

Diferentemente dos demais artigos desse dossiê esse artigo trata do tema com foco na análise histórica da trajetória das cinco mulheres trazendo contribuições para se pensar a formação e atuação delas dentro dos processos vividos nesses contextos históricos dos quais fizeram parte.

(C) ETD-Educação Temática Digital Campinas, SP v.19 n.2 p.307-315 abr./jun. 2017 
Entre reflexões sobre pesquisas vividas em contextos com crianças, jovens e professores, ensaios sobre cinematografias e contextos históricos específicos associados a personagens e filmes que relacionam cinema e educação, esse dossiê traz questões bem diferenciadas e que dialogam com os muitos debates dos estudiosos da área. Desejamos que ele possibilite a todos boas leituras e reflexões!

\section{REFERENCIAS}

BARTHES, Roland. A câmara clara: nota sobre a fotografia. Tradução: Júlio Castanõn. Rio de Janeiro : Nova Fronteira, 1984. 185 p.

DIDI-HUBERMAN, Georges. Que emoção! Que emoção? Tradução: Cecília Ciscato. São Paulo: Ed. 34, 2016. 72 p. (Coleção Fábula)

GUIMARÃES, César. O que ainda podemos esperar da experiência estética? In: GUIMARÃES, César; LEAL, Bruno Souza; MENDONÇA, Carlos Camargo. Comunicação e experiência estética. Belo Horizonte: Ed. UFMG, 2006. 210 p.

GUMBRECHT, Hans Ulrich. Produção de presença: o que o sentido não consegue transmitir. Tradução: Ana Isabel Soares. Rio de Janeiro: Contraponto: Ed. PUC-Rio, 2010. 206 p.

MACHADO, Arlindo. $O$ sujeito na tela: modos de enunciação no cinema e no ciberespaço. São Paulo: Paulus, 2007. 250 p.

WULF, Christoph. Homo Pictor: imaginação, ritual e aprendizado mimético no mundo globalizado. Tradução: Vinicius Spricigo. São Paulo: Hedra, 2013. 216 p. 